\title{
Submerged Plateau Implants: A Practical Solution for Mandibular Posterior Region
}

\author{
${ }^{1}$ Dhruvi H Shukla, ${ }^{2}$ Sonal M Anchlia, ${ }^{3}$ Nisarg P Patel, ${ }^{4}$ Vipul Nagavadiya, ${ }^{5}$ Rohit K Panwar, ${ }^{6}$ Hardi L Domadiya
}

\begin{abstract}
Introduction: Placement of endosseous plateau implants represents a valid treatment in the setting of limited alveolar bone height. This study's objectives were to evaluate the effect of submerging and platform switching on crestal bone loss and redistribution of occlusal forces, the advantage of plateau design in providing more surface area for osseointegration, and the outcome of autogenous bone grafting from the implant osteotomy site as an alternate to exogenous bone graft.
\end{abstract}

Materials and methods: A prospective study of 10 patients with mandibular posterior edentulism was selected. Preoperative alveolar bone height (mean $11.87 \mathrm{~mm}$ ) and width $(8.22 \mathrm{~mm}$ ) were measured on cone beam computed tomography. Twostaged implants were placed with $2.0 \mathrm{~mm}$ of submergence, which remained below the alveolar crest. The distribution of site according to bone quality and implant dimension was D2. Patients were followed up after 7 days for pain, infection, soft tissue dehiscence, and paresthesia followed by an average period of 1 year and evaluated for bone gain over implant shoulder, crestal bone loss, and peri-implant radiolucency.

Results: One-year postloading survival rates for submerged plateau implants was $100.0 \%$ in D2 bone, with no peri-implant radiolucency and statistically insignificant $(\sim 0-0.8 \mathrm{~mm})$ crestal bone loss.

Conclusion: Submerged plateau implants have excellent survival rates and crestal bone level maintenance. The results of this study support the hypothesis that plateau implants can be successfully used in mandibular areas with limited bone height.

Keywords: Autogenous bone graft, Crestal bone loss, Plateau, Platform switch, Sloping shoulder, Submerged.

How to cite this article: Shukla DH, Anchlia SM, Patel NP, Nagavadiya V, Panwar RK, Domadiya HL. Submerged Plateau Implants: A Practical Solution for Mandibular Posterior Region. Int J Oral Implantol Clin Res 2017;8(1):5-11.

Source of support: Nil

Conflict of interest: None

\section{INTRODUCTION}

"Life is short; Smile while you still have teeth." - A wonderful quote by Mallory Hopkins. Healthy teeth have an

\footnotetext{
1,3-6 Postgraduate Student, ${ }^{2} \mathrm{Head}$

1-6Department of Oral and Maxillofacial Surgery, Government Dental College \& Hospital, Ahmedabad, Gujarat, India

Corresponding Author: Dhruvi H Shukla, 1075/A Sector 2D Gandhinagar 382007, Gujarat, India, Phone: +917046228885 e-mail: dhruvi_shukla@ymail.com
}

important effect on one's diet, health, and overall sense of well-being, thus improving the quality-of-living. A single missing posterior tooth can lead to deleterious effects on one's health and lifestyle.

However, the posterior regions of the jaws have advanced alveolar bone resorption and, therefore, limited amount of bone and risks of injuring the inferior alveolar nerve. To overcome these, shorter implants should be used.

Short implant with plateau design takes advantage of long fins with narrow central bar, thus increasing the amount of implant surface available for osseointegration. The greater the implant surface, the lower is the per-unit pressure acting at such an interface. ${ }^{1}$

Submerging the implants provides bacterial seal and space for bone over the implant, which preserves the crestal bone and distributes occlusal stresses equally. Long-term preservation of the crestal bone makes the use of short implants predictable and encourages the clinician to use short implants in all kinds of bone dimensions and bone quality. The rocket-shaped module of a sloping shoulder can be considered as the ideal implant design for a homogeneous occlusal force distribution around the implant neck/crestal bone. ${ }^{2}$

The "plateau" design presents a unique healing pattern leading to rapid plateau filling with bone due to enhanced migration of osteogenic cells during early healing stages with high remodeling potential, leading to unique longterm Haversian-like bone morphology. ${ }^{3}$ The presence of plateaus (fins) on a short, more rounded implant provides a favorable shape and leads to considerably better dissipation of stresses and also prevents "rolling" of the implant. The macro-geometric design increases the area for ankylosis to bone (and, therefore, the surface area in intimate contact with bone).

In daily practice, one may often be challenged with patients who, although meet the ideal criteria for implant treatment, have insufficient bone. Bone grafting may partially solve the issue, but bone grafting is often expensive, time-consuming, has inherent risks and donor site morbidity, is an extra surgical procedure, and is often uncomfortable for the patient. This novel technique in our study minimizes the need for exogenous bone grafting by using autogenous bone graft from the same osteotomy site achieved with slow-speed sequential drilling of the bone. 
Sun et $\mathrm{al}^{4}$ evaluated the long-term failure rates of short dental implants $(\leq 10 \mathrm{~mm})$ and analyzed the influence of various factors on implant failure and concluded that among the risk factors examined, most failures of short implants can be attributed to poor bone quality in the maxilla or mandible and a machined surface. Short implants in atrophied jaws can achieve similar long-term prognoses as standard dental implants with a reasonable prosthetic design; however, stronger evidence is essential to confirm this finding.

Thus, this notion prompted a prospective clinical study to evaluate the use of submerged implants with plateau design using autogenous bone graft from the same osteotomy site. This entire study was done in an authentic and scientific manner abiding by the rules and regulations of the Ethics Committee.

\section{MATERIALS AND METHODS}

A prospective clinical study of 10 patients from November 2014 to December 2016 was done with an aim of maximizing implant placements possibilities in mandibular posterior edentulous areas with limited bone height. We also evaluated the effect of submerging and platform switching on crestal bone loss and redistribution of occlusal forces, the advantage of plateau design in providing more surface area for osseointegration, and the outcome of autogenous bone grafting from the same implant osteotomy site as an alternate to exogenous bone graft.

Before placement of implant, the inferior alveolar nerve proximity was measured from crest of alveolar bone to $1 \mathrm{~mm}$ above canal arbitrarily with digital orthopantomogram and confirmed by cone beam computed tomography (CBCT) (Fig. 1).

\section{Inclusion Criteria}

- Patients requiring implant treatment in the posterior mandible

- Absence of soft tissue and oral dental pathology and good general health

- Adequate amount of attached mucosa at edentulous ridge

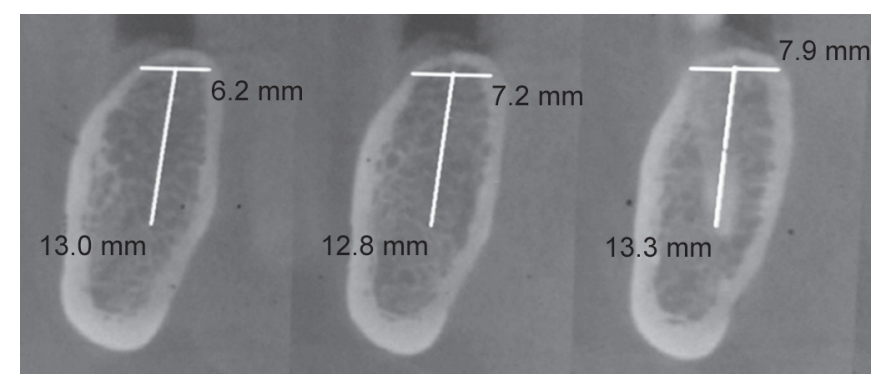

Fig. 1: Preoperative CBCT showing available bone height and width

\section{Exclusion Criteria}

- Uncontrolled metabolic diseases, compromised immune system, uncompensated systemic disease, hematologic disorders, pregnancy, prior radiotherapy of the surgical site, chemotherapy, osteoporosis, or any other systemic illness

- Compromised health of local site (e.g., local cyst, soft tissue ulceration, persistent infections, insufficient healing of previous extraction site)

- Patients with long-term habits of smoking, tobacco chewing, alcoholism, drug addiction, etc.

In this study, $5.0 \mathrm{~mm}$ diameter, $6 \mathrm{~mm}$ or $8 \mathrm{~mm}$ lengths of two-staged, submerged, endosseous plateau design titanium pressfit implants were used for single tooth replacement. Implants were supplied in a gamma sterile state with double packing.

\section{SURGICAL PROCEDURE}

Under the effect of local anesthesia $(1: 100,000)$, a midcrestal incision combined with two vertical-releasing incisions was made. The flap was then reflected and retracted to visualize the tooth-bone interface. A handpiece with 1:20 reduction gear was used at the low speed $(800-1200$ $\mathrm{rpm}$ ) high torque (35 Ncm) along with copious irrigation (external and internal) of normal saline to prevent thermal injury to the bone. Pilot hole was drilled with $2.0 \mathrm{~mm}$ pilot drill with external irrigation to a depth 2.0 to $3.0 \mathrm{~mm}$ deeper than the chosen implant.

The socket was widened with sequentially larger reamers until the same depth, without irrigation, at a maximum of $50 \mathrm{rpm}$ beginning with $2.5 \mathrm{~mm}$ diameter and ending with the diameter of the intended implant.

Harvested autogenous bone, intermittently removed from the flutes of the reamer burs, was placed into a silicone dappen dish for later use. Implant was seated in the prepared osteotomy site by tapping gently on the healing plug with an appropriate seating tip (Fig. 2) leaving the implant neck approximately $2 \mathrm{~mm}$ below the alveolar crest. The healing plug was cut to crestal bone level to ensure that no sharp edges remain that could irritate the soft tissue. The harvested bone graft was placed over the shoulder of the implant. Complete primary closure of the mucoperiosteal flap was done.

The implants were left for osseointegration for a period of 3 to 6 months after which the healing plug of the implant was exposed with a circular punch incision under local anesthesia and removed. Guide pin was placed to check integration and angulation. Excess bone was removed with sulcus reamer. The chosen abutment was inserted and fixed with tapping along the long axis of the abutment. 


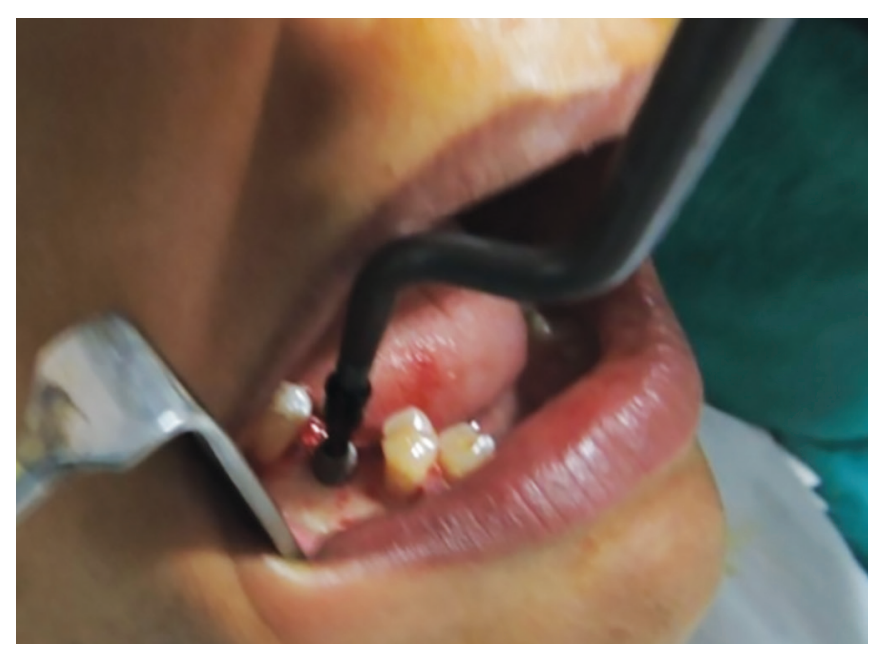

Fig. 2: Implant being seated in the prepared osteotomy site by tapping gently on healing plug with an appropriate seating tip

For making single crown, the putty wash impression technique was used. The impression was sent to the laboratory for fabrication of the crown. The prepared crown was checked for its passive fit to the abutment and lack of interference with the adjacent teeth. If needed, occlusal adjustment was done prior to cementation.

The patients were put on a systemic recall system for routine evaluation at the 1 st month, 3rd month, 6th month, then on an annual basis.

Each recall included evaluation of gingival inflammation and calculus, pus discharge, probing depth, prosthesis failure and keratinized mucosa, implant mobility, pain along with radiographic evaluation of peri-implant bone loss.

Response of the patient to rehabilitation with a single tooth implant was self-evaluated by the patient as bad, acceptable, good, or very good.

\section{RESULTS}

The present study was conducted to evaluate the efficacy of the novel technique of using submerged implants with plateau design using autogenous bone graft from the same osteotomy site.
In all cases except two, implants with a diameter of $5.0 \mathrm{~mm}$ and length of $8.0 \mathrm{~mm}$ were used. In two cases, implants with a diameter of $5.0 \mathrm{~mm}$ and length of $6.0 \mathrm{~mm}$ were used. The average alveolar height-average implant height is more than or equal to 3 to $4 \mathrm{~mm}$ to account for $2 \mathrm{~mm}$ for submerging the implant and 1 to $2 \mathrm{~mm}$ for safe distance from the inferior alveolar nerve. As we used two-staged implant with $2.0 \mathrm{~mm}$ of submerging, which remained below the alveolar crest bone, the implant was completely enclosed in the bone (Table 1).

The residual alveolar bone height was in the range of 9.0 to $14.00 \mathrm{~mm}$; on an average, it was $11.5 \mathrm{~mm}$ and alveolar bone width was in the range of 7.0 to $9.0 \mathrm{~mm}$. On an average, it was $8.0 \mathrm{~mm}$ at the site of implant placement in the mandibular premolar-molar region (Table 1).

On radiographic evaluation, $\sim 0.5$ to $2.2 \mathrm{~mm}$ preexisting and newly formed bone was found over the implant shoulder. Out of 10 implant sites, two sites $(20.00 \%)$ showed vertical bone loss of $0.8 \mathrm{~mm}$ without peri-implant radiolucency or infrabony pockets at the 1 year follow-up, which is not statistically significant (Table 2).

\section{DISCUSSION}

In the present study, out of 10 patients, 3 patients were from age group 31 to 40 years $(30 \%)$. Demirci et $\mathrm{al}^{5}$ in a 3-year retrospective study found that caries was most common among individuals aged 17 to 25 years. The proximal surfaces of incisors, canines, premolars, and occlusal surfaces in molars had the highest caries rates in all age groups, except for individuals older than 65 years. The incidence of caries decreases as age increases and periodontal problems become the primary etiology for tooth loss.

In our study, $5(50 \%)$ patients were male, while $5(50 \%)$ were females. Female dominance was a reported by Lukacs and Largaespada ${ }^{6}$ in their study, which is often explained by one of three factors: (1) earlier eruption of teeth in girls, hence longer exposure of girls' teeth to the cariogenic oral

Table 1: Distribution of implant dimension and preoperative alveolar bone height and width

\begin{tabular}{|c|c|c|c|c|c|}
\hline Case no. & Site of implant placement & $\begin{array}{l}\text { Preoperative alveolar } \\
\text { bone height }(\mathrm{mm})\end{array}$ & $\begin{array}{l}\text { Preoperative alveolar } \\
\text { bone width }(\mathrm{mm})\end{array}$ & $\begin{array}{l}\text { Implant } \\
\text { height }(\mathrm{mm})\end{array}$ & $\begin{array}{l}\text { Implant } \\
\text { width }(\mathrm{mm})\end{array}$ \\
\hline 1 & Mandibular left first molar & 12 & 8 & 8 & 5 \\
\hline 2 & Mandibular left second molar & 9 & 7.2 & 6 & 5 \\
\hline 3 & Mandibular right first molar & 13 & 7.9 & 8 & 5 \\
\hline 4 & Mandibular right first molar & 12.5 & 9 & 8 & 5 \\
\hline 5 & Mandibular right second premolar & 13.2 & 8.2 & 8 & 5 \\
\hline 6 & Mandibular left second premolar & 14.0 & 8.8 & 8 & 5 \\
\hline 7 & Mandibular left first molar & 12 & 8.5 & 8 & 5 \\
\hline 8 & Mandibular right second premolar & 13 & 8.6 & 8 & 5 \\
\hline 9 & Mandibular right first molar & 9 & 7 & 6 & 5 \\
\hline 10 & Mandibular right first molar & 11 & 9 & 8 & 5 \\
\hline
\end{tabular}

Height: from the alveolar crest to inferior alveolar canal; Width: between buccal and lingual cortical plates at alveolar crest 
Table 2: Radiographical evaluation of subcrestal implant site after 1 year of loading

\begin{tabular}{cllll}
\hline Case no. & Site of implant placement & $\begin{array}{l}\text { Bone gain over implant } \\
\text { shoulder }(\mathrm{mm})\end{array}$ & $\begin{array}{l}\text { Crestal/vertical } \\
\text { bone loss }(\mathrm{mm})\end{array}$ & $\begin{array}{l}\text { Peri-implant } \\
\text { radiolucency }\end{array}$ \\
\hline 1 & Mandibular left first molar & 2.0 & 0.5 & $\mathrm{~A}$ \\
2 & Mandibular left second molar & 0.5 & 0.8 & $\mathrm{~A}$ \\
3 & Mandibular right first molar & 2.2 & 0.1 & $\mathrm{~A}$ \\
4 & Mandibular right first molar & 1.6 & 0.3 & $\mathrm{~A}$ \\
5 & Mandibular right second premolar & 2.0 & 0.0 & $\mathrm{~A}$ \\
6 & Mandibular left second premolar & 2.0 & 0.2 & $\mathrm{~A}$ \\
7 & Mandibular left first molar & 2.0 & 0.2 & $\mathrm{~A}$ \\
8 & Mandibular right second premolar & 1.5 & 0.5 & $\mathrm{~A}$ \\
9 & Mandibular right first molar & 1.0 & 0.8 & $\mathrm{~A}$ \\
10 & Mandibular right first molar & 2.1 & 0.5 & $\mathrm{~A}$ \\
\hline
\end{tabular}

$\mathrm{A}=$ Absent

environment, (2) easier access to food supplies by women and frequent snacking during food preparation, and (3) pregnancy. The biochemical composition of saliva and overall saliva flow rate are modified in several important ways by hormonal fluctuations during events, such as puberty, menstruation, and pregnancy, making the oral environment significantly more cariogenic for women than for men.

We found that the most common reason for tooth loss was caries and mandibular first molar the most commonly affected. This finding is in corroboration with an article by Bhardwaj, ${ }^{7}$ who in a cross-sectional study of 1,200 patients concluded that first molars were most affected with dental caries than other teeth in both primary and permanent dentitions (48.93 and $78.69 \%$ respectively). Dental caries prevalence was high in mandibular arch than in the maxillary arch, i.e., 80.0 vs $77.38 \%$ in permanent dentition and 51.3 vs $46.56 \%$ in deciduous, dentition.

In the present study, preoperative alveolar bone height was in the range of 9 to $14 \mathrm{~mm}$, on an average $11.87 \mathrm{~mm}$, and preoperative alveolar width was in the range of 7.00 to $9.00 \mathrm{~mm}$, on an average $8.00 \mathrm{~mm}$. In the present study, two-staged plateau implant of $8.00 \mathrm{~mm}$ or less in length was used, which had an average $2.0 \mathrm{~mm}$ of submerging. Lee et $\mathrm{al}^{8}$ in their retrospective cohort study installed 613 plateau implants in 272 patients, submerging the sloping shoulder of plateau implant $2 \mathrm{~mm}$ below the upper end of adjacent alveolar bone, they observed that the failure rate was $3.01 \%$ while equicrestal (nonsubmerged) implants had a failure rate of $10.29 \%$.

Similarly, Degidi et $\mathrm{al}^{9}$ performed a retrospective histologic study to evaluate dental implants retrieved from human jaws that had been inserted in an equicrestal or subcrestal $(1-3 \mathrm{~mm})$ position and found that in all subcrestally placed implants, preexisting and newly formed bone were found over the implant shoulder. In the equicrestal implants, crestal bone resorption $(0.5-1.5 \mathrm{~mm})$ was present around all implants.
The bone quality was D2 in the maximum cases, i.e., 9 out of 10 cases $(90.0 \%)$ and in 1 case $(10.00 \%)$, it was bone D3.

In our study, all the patients prescribed a combination of amoxicillin and clavulanic acid and metronidazole for 5 postoperative days. None of the patients had pain, paresthesia, infection, or soft tissue dehiscence after implant placement. Bölükbaşı et $\mathrm{al}^{10}$ investigated the incidence of bacteremia, bacteriology, and antibiotic susceptibility against causative bacteria associated with dental implant placement done in 30 healthy patients. No bacteria were isolated at the baseline and 24 hours after surgery, whereas the prevalence of bacteremia at 30 minutes after dental implant installation was $23 \%$. The isolated bacteria species were Staphylococcus epidermidis, Eubacterium spp., Corynebacterium spp. and Streptococcus viridans. The S. epidermidis, which was isolated in three patients, was found to be resistant to penicillin, which is the first choice of many clinicians. McDermott et $\mathrm{al}^{11}$ found that the overall frequency of implant complications was only $13.9 \%$ (10.2\% inflammatory, $2.7 \%$ prosthetic, $1.0 \%$ operative), of which $53 \%$ were minor. Risk factors were smoking, use of onestage implants, and reconstructive procedures. We did not encounter any of the above-mentioned complications because none of the patients in our study had a habit of smoking, and surgery was also done in two stages.

In the present study, the implants placed at deeper crestal positions (1-3 mm sub crestal) contributed to the maintenance of the peri-implant mucosa texture and tonality and provided the reestablishment of the marginal tissue architecture similarly in a study by Pontes et al. ${ }^{12}$

On radiographic evaluation, $\sim 0.5$ to $2.2 \mathrm{~mm}$ preexisting and newly formed bone was found over the implant shoulder. Out of 10 implant sites, 2 sites $(20.00 \%)$ showed vertical bone loss of $0.8 \mathrm{~mm}$ without peri-implant radiolucency or infrabony pockets at the 1-year follow-up, which is not statistically significant, whereas the rest of the sites showed crestal bone loss of 0 to $0.5 \mathrm{~mm}$ (Fig. 3). Weng et $\mathrm{al}^{13}$ 


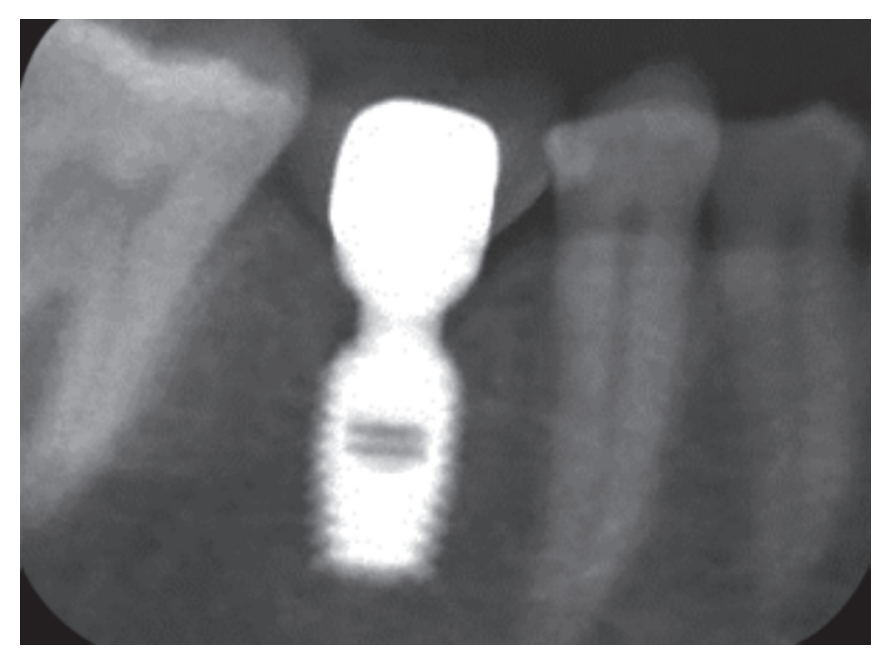

Fig. 3: Radiograph showing preexisting and newly formed bone over the implant shoulder with insignificant vertical crestal bone loss at the 1-year follow-up

and Welander et $\mathrm{al}^{14}{ }^{14}$ in two different studies, found that healing of implants placed in a subcrestal position could result in osseointegration to the abutment region of the implant (i.e., coronal to the implant-abutment junction). They observed that loss of peri-implant bone height was found only when the implants were placed equicrestally.

A cause of peri-implant bone resorption could be the presence of excessive stresses transmitted to the implantbone interface at the level of the alveolar crest with an overload and eventual microfracture of the bone structure. ${ }^{15}$ Using platform switching, or shifting, displacement of stresses away from the dense cortical bone and toward the trabecular bone could occur because the trabecular bone is more resilient, less dense, more flexible, and better adsorbs the functional stresses.

When an implant-abutment interface (IAI) is located at the level of the alveolar crestal bone, a significant inflammatory cell infiltrate with resorption of the alveolar bone around the crest occurs. ${ }^{16}$ The location of the implant shoulder subcrestally avoids the metal exposure and allows an adequate vertical dimension with an esthetic emergence profile. ${ }^{16}$ Lazzara and Porter ${ }^{16}$ in their study also showed that a smaller dimension of the abutment compared with the diameter of the implant (platform switching or shifting) can create an area around the circumference of the implant that helps to minimize the invasion of the biologic width. This fact could, in part, explain the reduced rate of bone resorption reported for this type of implant connection. The bacteria-proof seal, the lack of micromovements caused by the friction grip, and the minimally invasive secondstage surgery can also be important factors in preventing cervical bone loss. ${ }^{17}$

Traditional method to decrease the bite force on weaker bone has been to increase the implant surface area by increasing the length and/or diameter of the implant body.
When thread depth is increased along with the diameter, the functional surface area may increase more than 300\%. Such an increase in the surface area may decrease the stresses to crestal bone regions and reduce both crestal bone loss and early loading implant failure. A modified implant design, such as plateau with increased functional surface area (instead of total surface area) allows shorter implants with greater surface area to be used in all regions of mouth. Birdi et al, ${ }^{18}$ who did a retrospective cohort study in 194 patients with 5.7 or $6 \mathrm{~mm}$-long plateau implants, concluded that crown-to-implant ratios do not affect the success of short-length plateau design implants.

Gentile et $\mathrm{al}^{19}$ investigated the success rate of short implants $(6.0 \times 5.7 \mathrm{~mm})$ compared with long implants. Sample comprised 35 patients, in whom 172 implants were installed (45 short and 127 long). About 33 short implants were placed into the mandible's posterior region (73.3\%). After 12 months, the success rate reached $95.2 \%$ for short implants, and $95.2 \%$ for long implants, without statistically significant differences $(\mathrm{p}=0.78)$. The results suggested that short implants osseointegrate and support occlusal loads and concluded that survival of $6 \times 5.7 \mathrm{~mm}$ implants was comparable with that of non- $6 \times 5.7 \mathrm{~mm}$ implants.

Misch et $\mathrm{al}^{20}$ analyzed short implants inserted into the mandible's posterior area. In a 5-year follow-up, six losses were recorded (four in mandible and two in maxilla). Success rate reached $99.2 \%$. They stated that the area of most effort transmitted to implant is the bone crest, while the apical area receives less stress. Therefore, implant length may not be the most important factor in the distribution of loads at bone-implant interface.

Anitua et $\mathrm{al}^{21}$ described a new drilling system that allows the surgeon to obtain autologous living bone that is associated with plasma rich in growth factors and can be used in bone grafting. Bone particles collected using both conventional (approx. $800 \mathrm{rpm}$ ) and new drilling systems (50 rpm) were analyzed by means of optic and electronic microscopy in 10 patients. Microscopic examination showed that the bone structure and the presence of living cells in the bone chips were conserved in all samples obtained from drilling at low speed (50 rpm), whereas material obtained by conventional drilling did not maintain these qualities. Implantation techniques currently in use involve drilling at speeds of 1,000 to $1,500 \mathrm{rpm}$ to prepare potential recipient sites. The mechanical and thermal damages to the tissue surrounding the implant during drilling could have a destructive effect on the initial state of the cavity housing the implant. ${ }^{22,23}$ As a consequence, endogenous factors localized in bone extracellular matrix having a key role in the success of processes, such as bone regeneration and bone-implant integration may be damaged. The concept of slow drilling 
at $50 \mathrm{rpm}$ presented here has been suggested as an alternative to the conventional procedure. It provides a method for obtaining autologous bone during preparation of the surgical site, eliminating the need to collect bone from a second surgical area. If low-speed, nonirrigation drilling is used, it helps improve the quality of tissue obtained. Bone collected by this procedure has been shown by means of optic and electronic microscopy to be living bone. Bone collected by this procedure may be easier to manipulate than bone collected by other means and can provide adhesive and signaling proteins involved in bone repair. Irrigation washes away low-molecular-weight signaling proteins that play an active role in bone regeneration. ${ }^{24}$

Canullo et $\mathrm{al}^{25}$ evaluated that with platform switching, the IAI is displaced horizontally toward the center of the platform and separated from the marginal bone. Thus, bacterial infiltration, micromovements, and stress occur at a distance from the marginal bone, giving rise to lesser apical migration of the biological width and, therefore, less marginal bone resorption.

Lee et $\mathrm{al}^{8}$ inserted 308 platform switching implants with hydroxyapatite (HA)-coated necks and 305 titanium plasmasprayed implants. Some were placed at crestal level and others $2 \mathrm{~mm}$ subcrestal. The HA implants placed at crestal level failed 2.89 times more often than those positioned $2 \mathrm{~mm}$ below crestal level. This appears to show that when the rough surface is exposed to the oral environment, bacterial contamination and greater bone loss can be expected. In the case of platforms positioned at subcrestal level, the mucosal barrier increases while bone loss decreases.

Urdaneta et $\mathrm{al}^{26}$ did a retrospective cohort study to evaluate the effect of tooth-implant proximity using 235 plateau implants with platform switch that was designed to load bone coronal to IAI. They concluded that plateau rootform implant with a sloping shoulder in close proximity to adjacent tooth did not cause any damage to that tooth or lead to bone loss or failure of implant even if placed $<1 \mathrm{~mm}$ to adjacent natural tooth. This unique feature is because plateau root-form implants are seated into a similar-sized osteotomy without torqueing and without pressure to adjacent structures.

Demiralp et $\mathrm{al}^{27}$ retrospectively investigated cumulative survival rates of short implants $(<8 \mathrm{~mm})$ according to patient variables over a 5 -year period follow-up data that indicate that short implants with locking tapers and plateau-type roots have comparable survival rates as other types of dental implants. Herrmann $\mathrm{et}^{\mathrm{a}}{ }^{28}$ found implant failures were strongly correlated to patient factors, including bone quality, especially when coupled with poor bone volume ( $65 \%$ of these patients experienced failure). These reported failures are not primarily related to surgery healing, but instead occur after prosthetic loading.
However, a more comprehensive remark on the usefulness of the same implant in function can only be drawn after long-term follow-up of large number of cases.

\section{CONCLUSION}

Thus, overall, the use of submerged implants with plateau design is a viable therapeutic option in improving success for prosthesis of teeth in mandibular posterior edentulous area with limited bone height and reducing morbidity to the patient. Submerged plateau implants have excellent survival rate and crestal bone level maintenance. The results of this study support the hypothesis that plateau implants can be successfully used in mandibular posterior areas.

\section{REFRENCES}

1. Mataix MB, Garnelo ACN, Azpeitia JAC. Greater diameter implants after four years of experience. Nobel Biocare Global Forum 1996;10(3):8-9.

2. Marincola M, Coelho PG, Morgan V, Cicconetti A. The importance of crestal bone preservation in the use of short implants. J Adv Dent Res 2010 Oct;1(1):15-18.

3. BaldassarriM, BonfanteE,SuzukiM,Marin C, GranatoR, TovarN, Coelho PG. Mechanical properties of human bone surrounding plateau root form implants retrieved after 0.3-24 years of function. J Biomed Mater Res Part B 2012 Oct:100B(7):2015-2021.

4. Sun HL, Huang C, Wu YR, Shi B. Failure rate of short implant and factors influencing their failure: a systemic overview. Int J Oral Maxillofac Implants 2011 Jul-Aug;26(4):816-825.

5. Demircia M, Tuncera S, Yuceokurb A. Prevalence of caries on individual tooth surfaces and its distribution by age and gender in university clinic patients. Eur J Dent 2010 Jul;4(3):270-279.

6. Lukacs JR, Largaespada LL. Explaining sex differences in dental caries prevalence: saliva, hormones, and "life-history" etiologies. Am J Hum Biol 2006 Jul-Aug;18(4):540-555.

7. Bhardwaj VK. Dental caries prevalence in individual tooth in primary and permanent dentition among 6-12-year-old school children in Shimla, Himachal Pradesh. Int J Health Allied Sci 2014 May;3(2):125-128.

8. Lee EH, Ryu SM, Kim JY, Cho BO, Lee YC. Effects of installation depth on survival of an hydroxyapatite-coated Bicon implant for single-tooth restoration. J Oral Maxillofac Surg 2010 Jun;68(6):1345-1352.

9. Degidi M, Iezzi G, Scarano A, Piattelli A. Immediately loaded titanium implant with a tissue-stabilizing/maintaining design ('beyond platform switch') retrieved from man after 4 weeks: a histological and histomorphometrical evaluation. A case report. Clin Oral Implants Res 2008 Mar;19(3):276-282.

10. Bölükbaşı N, Özdemir T, Öksüz L, Gürler N. Bacteremia following dental implant surgery: preliminary results. Med Oral Patol Oral Cir Bucal 2012 Jan;17(1):e69-e75.

11. McDermott NE, Chuang SK, Woo VV, Dodson TB. Complications of dental implants: identification, frequency, and associated risk factors. Int J Oral Maxillofac Implants 2003 Nov-Dec;18(6):848-855.

12. Pontes AE, Ribeiro FS, Iezzi G, Piattelli A, Cirelli JA, Marcantonio E Jr. Biologic width changes around loaded implants inserted in different levels in relation to crestal bone: histometric 
evaluation in canine mandible. Clin Oral Implants Res 2008 May;19(5):483-490.

13. Weng D, Nagata MJ, Bell M, Bosco AF, de Melo LG, Richter EJ. Influence of microgap location and configuration on the periimplant bone morphology in submerged implants. An experimental study. Clin Oral Implants Res 2008 Nov;19(11):1141-1147.

14. Welander M, Abrahamsson I, Berglundh T. Subcrestal placement of two-part implants. Clin Oral Implants Res 2009 Mar;20(3):226-231.

15. Dhima M, Balshi T, Wolfinger G, Petropoulos VC, Balshi S. A retrospective analysis of mandibular bone height changes associated with 81 screw-retained implant-supported prosthesis with distal cantilevers: a long- term follow-up analysis. Int J Oral Maxillofac Implants 2013 May-Jun;28(3):854-859.

16. Lazzara RJ, Porter SS. Platform switching: a new concept in implant dentistry for controlling post restorative crestal bone levels. Int J Periodontics Restorative Dent 2006 Feb;26(1):9-17.

17. Chou HY, Müftü S, Bozkaya D. Combined effects of implant insertion depth and alveolar bone quality on peri-implant bone strain induced by a wide- diameter, short implant and a narrowdiameter, long implant. J Prosthet Dent 2010 Nov;104(5):293-300.

18. Birdi H, Schulte J, Kovacs A, Weed M, Chuang SK. Crown-toimplant ratios of short-length implants. J Oral Implantol 2010 Jun;36(6):425-433.

19. Gentile MA, Chuang SK, Dodson TB. Survival estimates and risk factors for failure with $6 \times 5.7-\mathrm{mm}$ implants. Int J Oral Maxillofac Implants 2005 Nov-Dec;20(6):930-937.

20. Misch CE, Steignga J, Barboza E, Misch-Dietsh F, Cianciola LJ, Kazor C. Short dental implants in posterior partial edentulism: a multicenter retrospective 6-year case series study. J Periodontol 2006 Aug;77(8):1340-1347.
21. Anitua E, Carda C, Andia I. A novel drilling procedure and subsequent bone autograft preparation: a technical note. Int J Oral Maxillofac Implants 2007 Jan-Feb;22(1):138-145.

22. Iyer S, Weiss C, Mehta A. Effects of drill speed production and the rate and quality of bone formation in dental implant osteotomies. Part II: relationship between drill speed and healing. Int J Prosthodont 1997 Nov-Dec;10(6):536-540.

23. Iyer S, Weiss C, Mehta A. Effects of drill speed on heat production and the rate and quality of bone formation in dental implant osteotomies. Part I: relationship between drill speed and heat production. Int J Prosthodont 1997 Sep-Oct;10(5): 411-414.

24. Bennett NT, Schultz GS. Growth factors and wound healing: biochemical properties of growth factors and their receptors. Am J Surg 1993 Jun;165(6):728-737.

25. Canullo L, Fedele GR, Iannello G, Jepsen S. Platform switching and marginal bone-level alterations: the results of a randomized controlled trial. Clin Oral Implants Res 2010 Jan;21(1):115-121.

26. Urdaneta RA. Seemann R, Dragan IF, Lubelski W, Leary J, Chuang SK. A retrospective radiographic study on the effect of natural tooth-implant proximity and an introduction to the concept of a bone-loading platform switch. Int J Oral Maxillofac Implants 2014 Nov-Dec;29(6):1412-1424.

27. Demiralp KÖ, Akbulut N, Kursun S, Argun D, Bagis N, Orhan K. Survival rate of short, locking taper implants with a plateau design: a 5-year retrospective study. Bio Med Res Int 2015 Apr;2015:8.

28. Herrmann I, Lekholm U, Holm S, Kultje C. Evaluation of patient and implant characteristics as potential prognostic factors for oral implant failures. Int J Oral Maxillofac Implants 2005 MarApr;20(2):220-230. 